\title{
The impact of community led alternative rite of passage on eradication of female genital mutilation/cutting in kajiado county, Kenya: A quasi-experimental study
}

Samuel Muhula ${ }^{1 *}$, Anthony Mveyange ${ }^{2}$, Samuel O Oti ${ }^{2}$, Martha Bande ${ }^{2}$, Hellen Kayiaa ${ }^{2}$, Charles Leshore ${ }^{1}$, David Kawai ${ }^{1}$, Yvonne Opanga $^{1}$, Enock Marita ${ }^{1}$, Sarah Karanja ${ }^{1}$, Eefje Smet ${ }^{3}$ and Hilke Conradi ${ }^{3}$

${ }^{1}$ Amref Health Africa in Kenya, Nairobi, Kenya

${ }^{2}$ Independent Research Advisors, Nairobi, Kenya

${ }^{3}$ Amref Health Africa in Netherlands, Leiden, Netherlands

\begin{abstract}
Background:In Kenya, Female Genital Mutilation/Cutting (FGM/C) is highly prevalent in specific communities such as the Maasai and Somali. With the intention of curtailing FMG/C prevalence in Maasai community, Amref Health Africa, designed and implemented a novel intervention - community-led alternative rite of passage (CLARP) in Kajiado County in Kenya since 2009. The study: a) determined the impact of the CLARP model on FGM/C, child early and forced marriages (CEFM), teenage pregnancies (TP) and years of schooling among girls, b) explored experiences and stories of CLARP and non-CLARP beneficiaries related to FGM/C, CEFM, TP and years of schooling and c) explored the attitude, perception and practices of community stakeholders towards FGM/C
\end{abstract}

Methods: We employed a mixed-methods design including quantitative and qualitative approaches.

Results: The CLARP has contributed to 1) decline in FGM/C prevalence, CEFM rates and TP rates among girls by $24.2 \%, 4.9 \%$ and $6.3 \%$ respectively. 2) increase in schooling years among girls by 2.5 years. Perceived CLARP benefits to girls included: reduction in early/teenage marriages and childbirth; increased school retention and completion; teenage pregnancies reduction and contribution to decline in FGM/C prevalence. Community stakeholders in Kajiado also strongly believe that CLARP has been embraced widely in the community because of its demonstrable impacts in the lives of its beneficiaries and their families.

Conclusion: This study demonstrated that CLARP has been positively received by the Maasai community and has played a decisive role in attenuating FGM/C, CEFM and TP in Kajiado, while also contributing to increasing girls' schooling years.

\begin{abstract}
Abbreviations: ARP: Alternative Rite of Passage; CBO: Community-Based Organisation; CLARP: Community Led Alternative Rite of Passage; CoG: Council of Governors; CPO: Children Protection Officer; CSO: Civil Society Organisation; DiD: Difference in Difference; CEFM: Child Early and Forced Marriage; ESRC: Ethics and Scientific Review Committee; TP: Teenage Pregnancy; FGD: Focused Group Discussion; FGM/C: Female Genital Mutilation/Cutting; ICF: Informed Consent Form; IDI: In-Depth Interview; KDHS: Kenya Demographic Health Survey; KII: Key Informant Interview; MCA: Member of County Assembly; NCPD: National Council for Population and Development; SRHR: Sexual Reproductive Health and Rights; TBA: Traditional Birth Attendant; UNFPA: United Nations Population Fund; UNICEF: United Nations Children's Fund; WHO: World Health Organization
\end{abstract}

\section{Background}

Female genital mutilation/cutting: Context, evidence and policy issues

Female Genital Mutilation/Cutting (FGM/C) is a global concern, particularly in Africa and the Middle East [1,2]. Although the prevalence has started to wane, especially in Africa, recent data reveal that FGM/C is still practised as a social norm and thus remains persistent and ubiquitous across countries. However, concerted international efforts and commitment to address FGM/C continue to grow. Countries have made strides in designing strategies, plans, policies and in passing laws against the practice in addition to resource mobilisation to support the efforts to eradicate FGM/C.

FGM/C is a cultural practice involving partial or complete removal and alteration/injury to the external female genitalia for non-medical reasons and it may take four key forms: partial or total removal of the clitoris (Clitoridectomy or Type I); partial or complete removal of the clitoris and labia (Excision, or Type II); narrowing of the vaginal opening (Infibulation or Type III); and other harmful practices such as incising, piercing or scraping of the genital area (Type IV) [3]. Statistics show global estimates of roughly 200 million women and girls who have undergone the FGM/C practise [4]. In Sub-Sahara Africa, approximately three million girls undergo FGM/C practice every year and half of the countries that practise FGM/C cut girls before the age of 5 while in other countries cutting occurs between 5 and 14 years of age [1,5].

${ }^{*}$ Correspondence to: Samuel Muhula, Amref Health Africa in Kenya, Nairobi, Kenya, Tel: +254721958734; E-mail: sam.muhula@gmail.com

Key words: impact evaluation, community led alternative rite of passage, female genital mutilation/cutting, harmful cultural practices

Received: April 08, 2020; Accepted: April 27, 2020; Published: April 30, 2020 
Muhula S (2020) The impact of community led alternative rite of passage on eradication of female genital mutilation/cutting in kajiado county, Kenya: A quasiexperimental study

Across most countries, girls and women victims have undergone either clitoridectomy or excision or both as part of cultural gender and social status identity, with traditional practitioners being the main perpetrators of the practice. Global FGM/C prevalence provides a spatial outlook of FGM/C prevalence and paints a gloomy picture that the practice is mainly concentrated across 29 countries from the Atlantic coast to the horn of Africa with a wide variation in the percentage of women and girls cut, both within and across countries. Most of the girls and women who have undergone the practice live in north-eastern, eastern and western parts of Africa where the practice is rife.

According to UNFPA FGM/C undermines, physiologically and psychologically, the health of women and girls in several ways. First, it can cause severe and deadly injuries that can result in such complications as haemorrhage and infections. Second, complications during pregnancy and childbirth and continue to be the leading cause of death among 15- to 19-year-old girls in most parts of the developing world. Third, FGM/C can cause serious health problems and pains. For-example, scarring, cysts, abscesses and tissue damage, infertility and pain during menstruation, urination and sexual intercourse which is more common to women and girls who have gone through Type III FGM/C. Finally, going through the FGM/C ordeal and the resultant psychological effects can have devastating effects on girls' and women's mental health [6].

\section{What is the status of FGM/C in Kenya?}

Out of approximately 125 million girls and women who underwent FGM/C by 2013, Kenya accounted for more than 9.3 million which is about 7.4 per cent of FGM/C cases [5]. FGM/C prevalence in Kenya shows FGM/C prevalence computed using 2003, 2008-2009 and 2014 demographic health surveys data. The left panel indicates that the overall prevalence declined from 31.8 per cent in 2003 to 21.6 per cent in 2014. The right panel shows the distribution across major Kenyan regions and indicates alarming FGM/C prevalence in North Eastern Kenya, with an average above 90 per cent across the three survey waves and Western Kenya recording the lowest prevalence below 5 per cent.

2014 FGM/C prevalence in Kenya shows the spatial distribution of FGM/C prevalence across Kenyan counties in 2014. Twenty-five counties (out of 47) in Kenya had higher than average prevalence. These counties include Mandera, Wajir, Marsabit and Garissa counties where prevalence was more than 90 per cent. At the other end of the spectrum are counties with low prevalence rates (less than 5 per cent). These include Kilifi, Uasin Gishu, Bungoma and Vihiga counties.

Within Kenya, there are also wide ethnic and cultural variations in the distribution of FGM/C prevalence. Ethnic differences appear to highly correlate with high prevalence in sub-regions and counties that are predominated by the Somali, Samburu, Kisii and Maasai communities at $94,86,84$ and 78 per cent, respectively [7]. Even the specific form of FGM/C practised varies across communities. For example, 75 per cent of the FGM/C exercised by Somalis are of the most severe Type III infibulation [8]. The Kisii and Maasai communities practice Type I clitoridectomy and Type II excision, respectively [9]. CEFM, TP and FGM/C are heavily interlinked [10]. Traditional beliefs and practices are also associated with high rates of child, early and forced marriages and teenage pregnancies in Kenya. Statistics show that up to 2.3 million girls in Kenya have had their first pregnancy at adolescent years, while 535,441 women aged between 20 and 24 had their first pregnancies by the age of 18 [11]. Additionally, child marriages remain high, at 23 per cent [12].
FGM/C practise also varied significantly across different age cohorts and ethnicities over time. FGM/C prevalence across age cohorts and ethnicity shows that not only has FGM/C been declining but it has been doing so across different age cohorts and ethnicities. The first panel reveals two key contradicting patterns. First, a steady decline in prevalence across years for all the age cohorts, which is consistent across the three survey rounds suggesting somewhat persistent but declining FGM/C practices. Second, disproportionate increases in prevalence across the different age cohorts in each survey year with older cohorts registering increases in the FGM/C practices. KDHS data also tells us that 2 per cent of circumcised women age 15-49 experience FGM/C Type I, 87 per cent had Type II, and 9 per cent Type III [13]. The data further show high mother-daughter correlations -- girls age 0-14 are more likely to go through the practice if their mother had undergone FGM/C - with 8 per cent of Kenyan girls age 0-14 having gone through FGM/C Type III. The second panel also shows a declining FGM/C trends in some ethnic groups -- Embu, Kalenjin, Kamba, Kikuyu, Mijikenda or Swahili on the coast, and Turkana -- but reveal a gloomy picture among the Kisii, Samburu and Somali ethnic groups - with not only high FGM/C rates (above 90 per cent) but also the rate of reduction over the years was minuscule signalling persistence of the practices.

Socioeconomic factors are also critical drivers of FGM/C practices in Kenya [7]. FGM/C prevalence by residence and wealth status indicates that prevalence was predominantly high for poor and rural girls and women. The left panel shows high FGM/C prevalence for women residing in rural relative to urban areas. The estimates are consistent in all three survey waves across the decade reinforcing the notion that traditional beliefs and practices, especially in rural areas, exacerbated FGM/C practices in Kenya. The right panel also shows persistently high prevalence among poor women in all survey waves suggesting that poverty could also somewhat explain the high prevalence, especially in rural areas.

Kenya has adopted several legal and legislative texts to eliminate FGM/C. Article 44 (3) of the Kenyan Constitution bars any person from compelling another person to perform, observe or undergo any harmful cultural practice or rite. Moreover, Article 53 (d) categorically states that children should be free from harmful cultural practices, inhuman and degrading treatment. Government of Kenya Laws and Policies on FGM/C which is a compilation of pieces of legal texts in Kenya that provide a framework for engagement with all stakeholders and provide protective measures for girls and women.

However, legal actions alone are inadequate to change attitudes and behaviours as it fails to address underlying socio-cultural drivers of FGM/C [14]. Rigid enforcement of the law may result in the unintended effect of encouraging difficult to detect approaches in effecting the cut, making reporting of prevalence difficult [15]. The CLARP intervention in Kenya is one of the classic models of community-led initiatives aiming at changing perceptions, attitudes, and behaviours towards FGM/C practices.

\section{Purpose of the impact evaluation}

Until recently when FGM/C prevalence started to decline, the practice had become a widespread social and health predicament in many parts of Africa, Asia and the Middle East [3-5]. Several factors are behind the recent turnaround of the FGM/C prevalence: the increased and improved levels of educational outcomes, changing social-cultural norms bolstered by enforced legal reforms and growing dissent voices against FGM/C practices and socio-economic development $[7,16,17]$. Like many other countries fighting the practice in Africa, Kenya has 
Muhula S (2020) The impact of community led alternative rite of passage on eradication of female genital mutilation/cutting in kajiado county, Kenya: A quasiexperimental study

also witnessed a downward trend in FGM/C prevalence. Shell-Duncan propose that the decline in FGM/C prevalence is partly because of community programmes such as the CLARP [18]. The CLARP model compliments efforts geared at ending FGM/C practices by creating awareness of their devastating physiological, psychological, and social effects on girls and women who undergo such traumatising experience. The model, which is implemented primarily in settings where FGM/C practices are rites of passage, provides alternate means through which communities can acknowledge the rite of passage with positive benefits on the wellbeing of the girls and women.

In Kenya, the CLARP model was first rolled out in Kajiado County in 2009 in line with the Anti-FGM/C vision to eradicate widespread FGM/C practices across the African continent by 2030 [19]. Kajiado county features prominently among counties with high prevalence for both teenage pregnancies and child marriages. Child marriage rates remain high, at 28 per cent [12]. Kajiado's school enrolment rates are marginally low and stand at 75 per cent and 26.3 per cent for primary and secondary school, respectively [20]. These statistics point to a lower school enrolment rate for secondary schools, influenced by, amongst other, harmful practices such as FGM/C and child forced marriages. High prevalence of FGM/C cases and child marriage with its resultant effect on high teenage pregnancies in Kajiado mainly inform various interventions by national, county governments and development partners, such as Amref Health Africa. Given these gloomy statistics in Kajiado, the CLARP intervention stands out as one of the essential community-led initiatives that have the potential to address FGM/C practices and the associated consequences. Therefore, CLARP model provides training targeted at reducing and eventually eliminating not only FGM/C but also CEFM and TP and improve girls' or women's levels of educational outcomes.

However, despite the declining trends in FGM/C prevalence, the extent to which the CLARP model had a role to play in such declines in Kenya, and particularly in Kajiado county remains unclear. Consequently, to shed light on the contribution of CLARP in the fight against FGM/C, the present study sought to quantitatively and qualitatively evaluate the impact of the CLARP in Kajiado.

\section{Evaluation objectives}

The main objectives of the evaluation were to:

1) Determine the impact of the community-led alternative rite of passage (CLARP) model on social and educational outcomes: Female Genital Mutilation/Cutting (FGM/C), child early and forced marriages (CEFM), teenage pregnancy (TP) and years of schooling among girls;

i1) Explore experiences and stories of CLARP and non-CLARP beneficiaries, relating to CEFM, TP and years of schooling and

111) Explore the attitude, perception, and practices of community stakeholders towards FGM/C.

\section{Evaluation questions}

1) Has the CLARP programme led to any impacts on social (i.e., FGM/C, child early and forced marriages, and teenage pregnancy) and education outcomes (i.e., years of schooling) of its beneficiaries?

i1) What are the experiences, stories and the status of the girls who have gone through the CLARP model?

111) What are the perceptions, attitudes, and practices of community stakeholders about FGM/C practices?

\section{Methods}

\section{Background}

To quantify and document the impacts of the CLARP the study used a two-tier approach: a quasi-experimental approach which is quantitative, and a qualitative approach involving structured in-depth interviews (IDIs) focus group discussions (FGDs) and key informant interviews (KIIs) in addition to a detailed desk review of relevant documents.

\section{Quantitative methodology}

\section{Econometric model}

The study employed a robust quantitative quasi-experimental method to quantify the impacts of the CLARP intervention. Specifically, the study used a difference-in-difference (DiD) approach to credibly quantify the impacts of the intervention which measures the average impacts of the CLARP roll-out on social and educational outcomes. The results were then compared with select counties with no CLARP before and after the intervention was rolled-out in 2009.

The DID approach - Kajiado vs control counties summarise the setting of the quantitative approach and illustrates the DiD framework used to assess the impacts of the CLARP. The DiD approach estimates the average effects of CLARP programme on FGM/C prevalence and other social and educational outcomes before and after its rollout in 2009 across Kajiado versus two sets of control counties with high and low prevalence of FGM/C:

1) Cluster 1 (left panel): The counties included are Mandera, Marsabit and Wajir which have the highest FGM/C prevalence as per 2003, 2008-2009 and 2014 KDHS data. Such CLARP intervention or a similar one, as late as 2015, was non-existent in these counties; and

i1) Cluster 2 (right panel): The counties included are Bungoma, Busia, Kakamega, Vihiga, Siaya, Homa Bay, Kisumu, Kilifi and Makueni which have both the lowest FGM/C prevalence and where the CLARP model was non-existent. These counties were test cases to explore any potential alternative explanations and run sensitivity checks to the baseline DiD estimates.

Below is the DiD specification:

$\mathrm{Y}_{c, t}=\alpha_{0}$ Post $_{t}+\alpha_{1}$ ARP $_{c, t}+\alpha_{2}$ Post $_{t} \times$ ARP $_{c, t}+X_{c, t}^{\prime} \alpha_{3}+$ District $_{d}+$ Year $_{t}$ + District $_{d} \times$ Year $_{t}+€_{c, t}$

Where $c$ and $t$ stand for counties and years, respectively. $Y_{c, t}$ measures the various health and educational outcomes of interest (i.e., female genital mutilation/cutting, child early and forced marriages and teenage pregnancy as well as girls' years of schooling). The study exploited the rich KDHS individual records data which captures information on women aged 15-49 and extracted and analysed the following key survey variables: (i) whether the respondent is circumcised or not, (ii) whether the respondent was married below 18 years, (iii) whether the respondent gave birth below 20 years, and (iv) education in single years. Notice that (i) to (iii) capture latent binary variables while (iv) captures continuous variable. Post $t_{t}$ is a binary indicator taking the value of 1 for years post 2009, and 0 otherwise. $\mathrm{ARP}_{c, t}$ is also a binary indicator taking the value 1 if the CLARP was rolled out in a county in 2009, and 0 otherwise. $\alpha_{0}$ captures the separate average effects of time before and after the CLARP rollout. $\alpha_{1}$ captures the average effect of being in a county with the CLARP versus the county with none. $\alpha_{2}$ captures the average effect of the CLARP rollout. Variable District ${ }_{d}$ stands for 
Muhula S (2020) The impact of community led alternative rite of passage on eradication of female genital mutilation/cutting in kajiado county, Kenya: A quasiexperimental study

district/sub-county fixed effects which include unobserved district/subcounty characteristics (e.g., cultural beliefs and practices, the difference in districts/sub-counties responses' on FGM/C issues including the level of effort and resources deployed by sub-county authorities, and unobserved geographical factors). Year ${ }_{t}$ stands for year fixed effects which include unobserved year effects specific to the different counties.

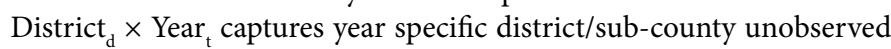
effects. $€_{c, t}$ is an error term that captures all the other residual factors not captured in the specified model. To address potential intra-cluster correlations, the standard errors of all coefficient estimates are clustered at the county level. The vector $\mathrm{X}_{c, t}^{\prime}$ captures time-varying observables that would otherwise confound the coefficient estimates of the CLARP roll-out effects. The control variables are: age at first cohabitation, age and sex of the household head, ethnicity, wealth index, age cohorts, residence (rural or urban) and religion. The inclusion of these variables attenuated the potential underlying bias that they could have on the average CLARP rollout effects.

\section{Quantitative data analysis}

To empirically investigate and respond to the first evaluation question, the study used KDHS data collected in 2003, 2008-2009, and 2014. The analysis used STATA 14 software. Calculations of FGM/C rates use KDHS binary indicator $(0=\mathrm{No}, 1=\mathrm{Yes})$ on responses of girls and women circumcision status. Education relies on school years in single digits while the construction of child early and forced marriages rates exploited the binary indicator $(0=$ Not Married, 1 Married at the time of being surveyed) and the age variable, allowing filtering of the sample to include the proportion of girls married below 18 years. Likewise, TP rates exploited binary indicator on current pregnancy status and age, thus generating proportions of young girls below 20 years who reported to be pregnant at the time of the survey.

Reports the summary statistics for girls and women aged 15-49 years across KDHS waves in 2003, 2008-2009, and 2014. The sample is divided into control (Wajir, Marsabit and Mandera counties) and treated (Kajiado county) groups, and the analysis compares the key summary statistics across the two groups. Except for FGM/C rates which are higher on control than in the treated groups, on average, the statistics indicate a close balance in both control and treated groups of the key outcome variables (schooling years, EFCM and ETP) and their potential confounders.

\section{Qualitative methodology}

The study used qualitative methods to gain a deeper understanding of the quantitative results and on the status of CLARP in Kajiado County. Therefore, to answer the second and third evaluation questions, the study employed qualitative approaches to examine the socio-economic benefits that have accrued to CLARP beneficiaries and capture perceptions and attitudes of stakeholders in Kajiado County. As previously noted, the analysis and findings of the qualitative survey provide a better contextual understanding of the underlying facilitators and barriers to the success of the CLARP in Kajiado. These were carefully triangulated with the results from quantitative estimations.

\section{Sampling procedure and recruitment of study participants}

The study used a three-pronged approach to draw the sample for the qualitative methodology. For In-depths Interviews (IDIs), a random sample of CLARP beneficiaries $(<5$ years post-graduation) drawn within a school from a randomly drawn list of schools in both Magadi and Oloitoktok. The underlying assumption was that most
CLARP beneficiaries in this category were students and still residents of both Magadi and Oloitoktok. CLARP beneficiaries with over five years post-graduation were randomly drawn from Amref's CLARP beneficiary's database and traced for interviews during the fieldwork. The stratification of respondents into recent ( $<5$ years post-graduation) and long-time ( $>5$ years post-graduation) graduates ensured that the interviews capture a broader range of experiences, especially from the latter category. Using Amref's database, the sampling filtered CLARP beneficiaries who joined and graduated from the programme between 2011 and 2016.

Sampling for Key Informant Interviews (KIIs) and Focus Group Discussions (FGDs) participants was purposive. KIIs participants included county government officials, local chiefs, religious and cultural leaders, children protection officers, community-based officers, members of county assembly, grandparents, traditional birth attendants, and teachers. FGDs participants included adolescent boys and girls, young men and women, Morans, and male and female parents.

Besides being included in the sample, eligibility to the study required potential respondents to be residents of the study areas and be willing to participate in the study voluntarily.

\section{Data collection tools}

The study used a theoretically grounded qualitative methodology to provide analysis of in-depth, existential accounts and perspectives of the sampled respondents using the standard qualitative data collection techniques: in-depth interviews (IDIs), KIIs and FGDs. IDIs applied to CLARP beneficiaries (women and girls aged 15 years and above who had graduated from the CLARP programme) and aimed at capturing the experiences and views of CLARP beneficiaries. IDIs also applied to non-CLARP beneficiaries (women and girls aged 15 years and above who did not participate in the CLARP training) as comparison group. As shown later in the results section, IDIs captured and documented individual stories, case narratives and respondents' status on outcome variables: FGM/C, child early and forced marriages, teenage pregnancies, and educational outcomes.

KIIs and FGDs were employed to conduct detailed qualitative inquiries with various stakeholders to evaluate their experiences, perceptions, attitude and practices towards FGM/C. KIIs probed selected stakeholders to understand their interaction, working, success and suggestions for improving FGM/C interventions. FGDs probed cross-sections of key community members including the CLARP beneficiaries, young boys and girls, Morans and parents. All the qualitative data was collected in the month of September 2019. FGDs were conducted across individual sub-groups to ensure that the interactions within the sub-groups led to a free and open expression of perspectives $[21,22]$.

\section{Respondents' characteristics}

Except for a Member of County Assembly in Magadi and religious leader as well as young women FGD in Oloitoktok, the study surveyed all the targeted respondents totalling 62 interviews.

\section{Qualitative data analysis}

The researchers familiarised themselves with the data by reading the transcripts, from which they developed the coding scheme, later loaded in NVIVO 11 software for coding and analysis. The coding scheme built on prior themes from the literature review, research questions and interview guides. Additional nodes/codes that represented emerging 
Muhula S (2020) The impact of community led alternative rite of passage on eradication of female genital mutilation/cutting in kajiado county, Kenya: A quasiexperimental study

themes not covered in the interview guides were added to the original codebook, constituting the grounded codes. A synthesis of the coded data using a framework matrix preceded thematic analysis to identify patterns of meaning or concepts that frequently occurred across interviews/coded data.

\section{Study area}

Kajiado County covers an approximated area of 21,000 sq.km and is adjacent to Nairobi, the capital city of Kenya. Kajiado county consists of several administrative districts including Kajiado Central, Isinya, Oloitoktok, Magadi, Mashuru, Namanga and Ngong. The subcounties are Kajiado North, Kajiado West, Kajiado central, Kajiado East and Kajiado South. Magadi and Oloitokitok, where Amref rolled out the CLARP for the first time in 2009, were identified areas used for qualitative surveys.

The county has an estimated population of about $1,117,840$ people as per 2019 census, a total of 316,179 households and an average household size of 3.5 [21]. The economy thrives mainly on agriculture and related activities including food crop farming, livestock production, dairy and beef production, hides and skins, poultry and horticulture.

\section{An overview of the CLARP model}

In 2009 Amref Health Africa in Kenya, designed and implemented a novel intervention - dubbed Community Led alternative rite of passage (CLARP) -- aimed at curbing the devastating FGM/C prevalence in the country. Successfully piloted and rolled out in Kajiado county, this community-led intervention sought to change social norms and reverse the alarming trends in FGM/C rates in Kajiado by involving and engaging community stakeholders including cultural leaders, Morans, traditional birth attendants, County Governments, religious and cultural leaders. The whole CLARP process takes 6-48 months to complete, and it entails several steps as summarised in below:

Step 1: Context analysis which involve engaging stakeholders such as cultural leaders, Morans, female circumcisers/TBA's, County government department and religious leaders

Step 2: Community Led ARPs Triggering which involve structured community dialogues

Step 3: Sensitization and training of Cultural Elders, Morans, women groups and circumcisers where communities define their own CLARP process

Step 4: Community mobilization, sensitization \& training which involve collaboration with CSOs (e.g. local women groups, youth-led organisations, etc) and capacity strengthening of the CSO's through sub-grants

Step 5: CLARP 3-days training of boys and girls on sexual and reproductive health rights, positive norms \& values, self-esteem, life skills.

Step 6: CLARP ceremony with girls' graduation through CLARP, blessing by Cultural elders and leaders', Public denouncement of FGM/C

\section{Step 7: Sustaining FGM/C free communities}

The key outcomes of the CLARP interventions include the establishment of a community movement that takes action to transform social and gender norms that perpetuate FGM/C, child early and forced marriages and teenage pregnancies. At the core of the CLARP, are boys and girls who are engaged and supported to know and claim their sexual reproductive health rights and take informed action when deprived of their rights. The CLARP model fosters community-led discussions and empowers not only girls and women, but also policymakers and community leaders to develop and implement local laws and policies on FGM/C and its adverse manifestations. In the end, the intervention aims to protect girls and women from FGM/C, measured by reduction in FGM/C cases, reduced cases of both child early and forced marriage and teenage pregnancy, and improvement in secondary school completion rates.

\section{Results}

We present both the quantitative and qualitative findings regarding the impacts of CLARP on FGM/C prevalence, CEFM, TP and years of schooling among girls in Kajiado County.

Pre-CLARP intervention balance check of outcome variables is a balance check of outcome variables pre-CLARP. The test of means is based on estimated residuals of regression equations with all four outcome variables. The result indicates no statistically discernible differences in the levels of outcome variables before the introduction of the CLARP in Kajiado.

Summary of difference-in-difference regression results presents a summary of the difference-in-difference regression results. Difference in Difference regression results. Column 1 shows the estimated outcomes of interest. Column 2 provides averages of the outcome variables between the control group counties (i.e., Mandera, Marsabit, and Wajir) and Kajiado (the treated County) before the rollout of the CLARP. Columns 3 and 4 report the estimated average treatment effects following, consecutively, the magnitude of the average effect and the sign of the effect. Columns 5 report the percentage impact change calculated as a mean of the estimated average effect divided by the overall mean pre-CLARP rollout - (reported as a factor change) on all outcome variables. Overall, the reported results indicate the average treatment effects before and after CLARP rollout in Kajiado compared to control counties.

The summarised results were estimated from fully specified models controlling for all relevant variables that can, in theory, bias the estimated average treatment effects. See section 2.2.1 for the model.

\section{Theory and existing literature}

guided the inclusion of these variables in the analysis [1,5,13,2325]. The potential variables are the age of respondents, age and gender of household head, age at first cohabitation, residence (rural or urban) status, religion, ethnicity and wealth index included in the analysis. For coherence and clarity, the results are presented in four themes as below.

\section{Impact of CLARP on FGM/C}

The results suggest that FGM/C prevalence declined by 24.2 per cent in Kajiado county compared to Wajir, Mandera, and Marsabit. The analysis of qualitative findings also corroborates the reported quantitative impacts on FGM/C. Qualitative findings indicate declining FGM/C prevalence in both Magadi and Oloitokitok. Study participants generally regarded CLARP as one of the significant contributors to the declining levels of FGM/C in the study communities. The findings show that there was a sense that Amref need to continue with the intervention for FGM/C to continue to decline.

The CLARP also appears to have generally contributed to a paradigm shift in the community by normalising the open conversation 
Muhula S (2020) The impact of community led alternative rite of passage on eradication of female genital mutilation/cutting in kajiado county, Kenya: A quasiexperimental study

about the culture of FGM/C, increasing enlightenment about its harms, changing mind-sets and empowering families to make better decisions.

\section{Impact of CLARP on child early and forced marriage (CEFM) rates}

Quantitative analysis shows that CLARP had discernible impacts on CEFM rates in Kajiado compared to control counties. The estimates show that CEFM declined by 4.9 per cent. The estimates are equivalent to a factor of four impact reduction in CEFM.

The analysis of CEFM using the qualitative data shows that CLARP models helped girls and women to make more informed decisions on delaying marriage and childbirth. The analysis shows that all the interviewed CLARP beneficiaries indicated that they would only think about marriage once they have completed their education. Usually, when a girl experiences FGM/C, they are now considered by the community to be mature and ready for marriage. However, CLARP appears to have empowered its beneficiaries to choose when to get married.

\section{Impact of CLARP on teenage pregnancy (TP) rates}

CLARP also appear to have had measurable quantitative impacts on TP rates in Kajiado compared to control counties. The analysis reveals that TP declined by 6.3 per cent (from an average of 1.5 to -7.8 per cent), which is also equivalent to a factor of four impact reduction. Qualitative analysis also backs up this finding. Majority of the respondents indicated that the CLARP intervention had led to a decrease in the number of teenage pregnancies.

This apparent reduction in teenage pregnancy was linked to the reduced likelihood of CLARP beneficiaries to be married off early as compared with non-beneficiaries. CLARP beneficiaries were also said to have higher self-worth and consequently, a lower likelihood of engaging in risky sexual behaviours.

However, not everyone agreed that CLARP had any differential impact on TP. One participant mentioned that although the CLARP model has led to a reduction in teenage pregnancies, there are still some uncut girls that become pregnant because of peer pressure.

\section{Impact of CLARP on educational outcomes}

Quantitative analysis also shows that CLARP had a tangible impact on improving educational outcomes in Kajiado compared to control counties. The estimates suggest that CLARP interventions in Kajiado resulted in an average increase in schooling years for girls and women by roughly 2.5 years.

Improvement in school retention and completion also came out of the analysis of the qualitative data further reinforcing the estimated quantitative impacts. The analysis shows that there was a consensus that CLARP beneficiaries were more likely to complete school as compared to the non-beneficiaries.

The increased likelihood of school completion among CLARP beneficiaries was attributed primarily to the decreased likelihood of early marriage. ARP beneficiaries appear to have a stronger agency to resist early marriage so that they could complete school.

Qualitative analysis also included an analysis of the experiences and stories of CLARP (versus non-CLARP) beneficiaries (DEQ 2) and the perceptions, attitudes, and practices of community stakeholders about FGM/C practices (DEQ 3). Section 3.5 and 3.6 report the analysed results in response to DEQ 2 and 3, respectively.

\section{Experiences and stories of CLARP versus non-CLARP beneficiaries}

This section reports on the experiences and stories of girls exposed to the CLARP intervention and their perceptions of various community stakeholders regarding the CLARP model and how it has impacted the practice of FGM/C in their communities.

Overall, CLARP beneficiaries reported having positive experiences with the program. They pointed out that they had learnt a lot from the program, such as the adverse effects of FGM/C. The uncut beneficiaries also mentioned that because of the CLARP interventions, they had escaped undergoing the cut and felt empowered to make decisions on their lives, including whether to undergo FGM/C or to remain in school.

Even among CLARP non-beneficiaries, there was a general sense that the CLARP had made a positive difference in the lives of its beneficiaries.

\section{Perceptions, attitudes, and practices of community stakeholders about FGM/C practices}

This section reports the analysis on the perceptions, attitudes, and practices of community stakeholders about FGM/C practices in Kajiado. The analysis shows a strong consensus that the study communities embraced the CLARP model because of its demonstrable impacts in the lives of its beneficiaries and their families. However, there remain some barriers to the model's full effectiveness. These barriers correlate with the perceptions, attitudes and practices of community stakeholders about FGM/C. This section highlights some of these barriers. It also identifies opportunities to refresh and reinvigorate the CLARP for better and more sustainable impact.

\section{Barriers}

\section{Resistance to cultural change}

Most of the study participants said they do not see any risk or disadvantage of the CLARP model. However, a few people mentioned that the key barrier to the program is the fact that it is still perceived to go against the Maasai culture.

The Morans, young men and elderly community members (such as grandparents) were particularly resistant to CLARP because they believed in the sacredness of the FGM/C practise even though they tended to accept that the practice did not provide any tangible benefits.

\section{Persistent stigma}

One daunting consequence of the resistance to cultural change is the persistence of stigma. Girls who do not undergo the cut, including those that graduate from the CLARP training remain at high risk of ridicule, discrimination and rejection in the community. Uncircumcised girls/ women are looked down upon by the community and endure namecalling using such derogatory terms as 'entaapai' (uncircumcised). Regardless of their age or educational status, uncircumcised girls are considered by many to be children since they have not undergone the traditional rite of passage into womanhood. In some instances, society looks at them as non-Maasai or aliens.

\section{Peer-pressure}

CLARP beneficiaries face significant peer-pressure, particularly from young men as well as girls that have undergone the cut. At the core of this peer-pressure are the issues of dating and marriageability. 
Muhula S (2020) The impact of community led alternative rite of passage on eradication of female genital mutilation/cutting in kajiado county, Kenya: A quasiexperimental study

Generally, male suitors prefer girls that have undergone the cut. These girls waste no time in flaunting the attention and gifts they receive.

\section{A rise in secret circumcisions}

One worrying trend that was highlighted by several study participants was the rising practice of FGM/C in secret. The illegality of FGM/C was driving several covert practices including conducting the cut in the dead of the night or sending the girls across the border into Tanzania.

\section{Opportunities to improve/adapt}

\section{Correcting misperceptions about uncircumcised girls}

There remain several misperceptions about uncircumcised girls, especially among young men and Morans. For example, uncircumcised girls were reported to be more sexually active and tend to conceive faster than those who have undergone the cut. Some respondents highlighted that uncircumcised girls were promiscuous, and hence men prefer the circumcised, less promiscuous women. Education and awareness programmes that target the misinformed groups can correct such misconceptions.

\section{Highlighting economic empowerment}

Some study participants highlighted that circumcision is associated with economic gains because girls are married off soon after the circumcision. Thus, the dowry payment was highlighted as an economic motivation for parents (especially fathers) to have their daughters circumcised in readiness for marriage and in anticipation for dowry payment. It also emerged that the dowry price for circumcised girls is higher than that of uncircumcised girls.

However, the narrative appears to be changing. The community is now witnessing a new economic phenomenon involving uncircumcised girls that have completed their studies and gone on to pursue successful careers. These girls then support their parents financially. Given the feedback that the CLARP intervention improved school completion rates among its beneficiaries, therein lies an opportunity for the model to educate the community about the long-term economic empowerment of girls that have passed through the program.

\section{More visibility to the harms of FGM/C}

Another opportunity lies in further educating the community members about visible harms of FGM/C. Young boys appeared quite knowledgeable about these harms, which they mentioned to include high risks of sexually transmissible diseases, complications during childbirth and school drop-out. These young men could be current and future ambassadors of the ARP interventions to the broader community.

Other ambassadors of change could include the Traditional Birth Attendants (TBAs) who were typically the people responsible for executing the cut. The analysis suggested a declining role of TBAs and that some of them are embracing a new way of thinking.

\section{Follow-up and reaching excluded groups}

According to some study participants, improvements of the ARP model would require reaching out to specific groups that were not adequately involved in the implementation of the intervention. These include small community-based groups, older men and women, parents and men who are the household heads. They also stressed the need for follow-up with former CLARP participants to ensure they adhere and live by CLARP training expectations consistently to help beneficiaries not to succumb to peer pressure and backslide to becoming FGM/C victims.

\section{Law enforcement and political will}

It was evident from the interviews that the study communities were aware of the laws of the land in so far as FGM/C is concerned. Several participants mentioned that the risk of arrest and prosecution had served as a significant deterrent to FGM/C in their communities. However, some participants were unconvinced that the laws were being enforced adequately, especially by some local chiefs. Others were worried about being stigmatised for cooperating with law enforcement officials. Future ARP interventions should, thus, consider how best to work with government officials to socialise and implement the respective anti-FGM/C laws.

\section{Discussion}

Existing empirical evidence on the interplay between FGM/C and CLARP models indicate that the latter plays a significant role in shifting knowledge, attitudes, and perceptions of FGM/C practices in a society $(1,3,23,25-28)$. By catalysing influence on its abandonment, CLARP models have directly and indirectly contributed to the declining FGM/ C's prevalence rates, improved educational outcomes for girls, and reduction in child early and forced marriages and teenage pregnancies $[1-3,18,29]$ assert that the effectiveness of the CLARP models hinges on its community-led approach in changing social norms on FGM/C, as well as empowerment of girls and women through education.

Much of the existing literature on the evaluation of CLARP models have centred on their impacts on community knowledge, attitudes, and perceptions [1,3,23,25-30].

Nevertheless, there is growing recognition that CLARP can have farfetched impacts beyond changing the social norms and behaviours on FGM/C [3,15,31]. Despite these recognitions and widely celebrated impacts of CLARP models in changing societal norms and behaviours towards $\mathrm{FGM} / \mathrm{C}$, scant evidence exists on the quantitative and qualitative impacts of CLARP models in not only reducing FGM/C prevalence but also in reducing child early and forced marriages, teenage pregnancies and improvement in educational outcomes. The present evaluation study bridges the existing knowledge gap by quantitatively and qualitatively evaluating the impacts of the CLARP model in Kajiado county in Kenya.

Employing quasi-experimental and qualitative methods to sleuth and analyse detailed quantitative and qualitative survey data, the findings of this study lend credence to the claim that the rollout of the CLARP model reduced FGM/C practices, child early and forced marriages, teenage pregnancies and improved girls' schooling years in Kajiado. Quantitatively, the estimated magnitude of impacts indicates that CLARP reduced FGM/C by 24 per cent, reduced early and forced child marriages and early teenage pregnancies four-folds over, respectively, and increased schooling years by 2.5 years. Further analysis of KDHS data also broadly corroborate these findings: not only have FGM/C prevalence been on the decline as depicted, but CEFM and TP have also been on the decline. CEFM declined from an average of 1.22 per cent in 2003 to 0.37 per cent in 2014. TP declined from an average of 1.29 per cent in 2003 to 0.38 per cent in 2014 . On the other hand, the average years of schooling increased from 6.87 years in 2003 to 9.3 years in 2014 .

Despite the reported barriers, qualitatively CLARP interventions appear to not only have left positive experiences to its beneficiaries 
Muhula S (2020) The impact of community led alternative rite of passage on eradication of female genital mutilation/cutting in kajiado county, Kenya: A quasiexperimental study

but also improved their lives. The analysis also shows that the CLARP has several perceived benefits to its beneficiaries: empowering girls to make decisions to delay marriage and childbirth and thus pursue the accumulation and development of their human capital. Finally, the findings reveal that Maasai communities in two sub-counties of Kajiado (Oloitokitok and Magadi) have embraced the CLARP model because of its tangible positive effects on young girls' lives in these communities.

The findings reported in this study are also consistent with those of the Yes I Do Alliance (YIDA) programme (31) which also point to a reduction in child marriages, teenage pregnancies and FGM/C prevalence as a result of community engagement and sensitisation on gender equality and sexual and reproductive health knowledge. YIDA's interventions aim at promoting gender-transformative thinking, girls' empowerment and engagement of men and boys as gatekeepers. The five (5) year programme (2016-2020) is working with vulnerable communities to end FGM/C, teenage pregnancies and child marriages in Ethiopia, Kenya, Malawi, Mozambique, Zambia, Pakistan, and Indonesia. In Kenya, the programme works within the Maasai community to provide an ARP to girls, with more than 1,300 girls having been trained and graduated from the programme. A mid-term review of the programme indicates a positive influence on community perspectives on deeply rooted cultural norms such as FGM/C, with community members appreciating the importance of girl child empowerment through education, which consequently is delaying child marriages and teenage pregnancies.

The findings of the present study have important policy implications for policymakers, health development practitioners, and Amref Health Africa. The findings provide persuasive evidence that CLARP models not only works but has discernible impacts on its beneficiaries in Kenya providing scope for scaling-up the models to other areas and countries where FGM/C practices are widespread and rampant. By extension and in line with other studies $[1,26,29,32,33]$ the results suggest that harnessing and mainstreaming CLARP interventions into, for example, education curricular and community-led outreach programmes, can have more tangible and sustainable impacts on both its beneficiaries and the society at large.

Efforts by governments, multi-lateral organisations and communityled initiatives have driven recent declines in FGM/C rates in Africa $[15,17]$. The fact that CLARP interventions have had positive impacts in Kajiado gives hope, at least on the margin, for yielding substantial results if scaled-up. Presumably, the positive CLARP effects signal the need for, amongst others, more resource mobilisations to entrench the interventions further interior to the rural and grassroots areas to effectively fight the persistent FGM/C practices standard in such places.

Typically, FGM/C, child early and forced marriages, teenage pregnancies and girls' educational outcomes are interlinked $[3,5,24,34,35]$. Thus, the documented positive findings suggest that the CLARP models can act as a safe bet for replacing FGM/C rituals as a rite of passage and at the same time be an educational and empowerment conduit for empowering girls and women in Kenya. The findings also signal the potent role CLARP have in lessening and curtailing the alarming rates of child early and forced marriages $[13,34]$ and thus contain its spill over effect to teenage pregnancies [35] minimising maternal death and childbirth complications associated with teenage pregnancies $[5,36]$. Spearheading the FGM/C fight in Kajiado, alongside governments, local and international, Amref Health Africa's CLARP model, is evidently, a force to reckon. The contribution of CLARP interventions in the fight against FGM/C practices and their related manifestations not only signal Amref Health Africa's noble work but also suggest more resources and collaborative efforts from other stakeholders are needed to scale-up the CLARP interventions to eradicate FGM/C.

\section{Study Limitations}

The quantitative analysis relied on slightly dated data between 2003 and 2014 because current data for 2018 is unavailable. The estimated impacts of CLARP may have worked during the period 2003-2014 only. While the quantitative analysis resonates with the attribution aspect, the analysis focuses on the entire Kajiado County with the assumption that Amref rolled out CLARP in the whole of Kajiado County, though this was not the case. Therefore, the analysis provides upper-bound estimates as it encompasses the entire County while intervention rollout was done in specific hotspots of Magadi and Oloitokitok. Moreover, the direct attribution to the Maasai community is hard to make because of the presence of multiple ethnicities that live in Kajiado and practice FGM/C.

Additionally, we could not use the parallel trends assumption test due to data gaps. we instead did a balance check of the outcome variables before the introduction of the intervention.

\section{Conclusions}

The study revealed that CLARP played a decisive role in attenuating FGM/C, CEFM and TP in Kajiado County. The results also indicate that the intervention increased schooling years for girls in the county. Furthermore, the findings show that the CLARP is slowly being embraced by the Maasai communities in Magadi and Oloitokitok subcounties and its implementation has left positive experiences on the ground. Additionally, the intervention empowered girls and women to claim and protect their social and human rights and accumulate more human capital, aside from further improving their lives. It will be important to re-run the analyses when the 2018 KDHS data will be available to see whether observed impact still hold.

\section{Declarations}

\section{Ethics approval and consent to participate}

Ethics approval for this study was acquired from Amref Ethical Scientific and Research committee, with reference number: - AMREFESRC P677/2019. All individual interviews were conducted in a private setting. The fieldwork team provided the participants with an Informed Consent Form (ICF) in Kiswahili/Maasai/English (depending on the language the participant is most comfortable with). The ICF included a section for seeking the assent of participants under the age of 18 years but above 15 years in addition to seeking consent from parents to the minors. Interviews were only conducted for participants who signed the ICF. Interviews were only recorded after express permission from participants.

\section{Availability of data and material}

KDHS data used in this study is available at https://dhsprogram. com/Data. All qualitative data supporting the findings of this study are available as presented in this paper.

\section{Funding}

This evaluation was made possible through the generous funding from Amref Health Africa Netherlands Office. The funders reviewed the manuscript and provided approval for publication 
Muhula S (2020) The impact of community led alternative rite of passage on eradication of female genital mutilation/cutting in kajiado county, Kenya: A quasiexperimental study

\section{Authors' contributions}

SM conceptualized the study. DK, YO, EM, SK, ES and HC contributed to the study design, critiqued, reviewed and revised the manuscript including contributing to the refinement of the initial research idea. AM, SOO, MB and $\mathrm{HK}$ did data collection and analysis. AM and SM took primary responsibility of interpretation of study results and writing the manuscript. CL, MB and HK took lead in organizing, guiding and supervision of field logistics during data collection. DK provided oversight for social aspects of the study and supervised implementation of the project activities in Kajiado County. $\mathrm{MB}$ reviewed and summarized literature. ES and HC took the lead in mobilizing resources within the Amref Health Africa Netherlands office. All authors read and approved the final manuscript for publication.

\section{Acknowledgement}

We thank all the research assistants who worked tirelessly to ensure that the data collected was of quality. These are Lester Linti, Joshua Kelele, Gideon Kanchori, Felistus Nashipae, Rachel Matayen, Alex Sananka, Thomas Tuke, Janet Seleina and Rachel Lemaikai. We are also grateful to Amref Health Africa drivers:- Samuel Mukabana and Rufas Njuguna for ably driving the field team through the rough terrains of Kajiado County.

\section{References}

1. United Nations Children's Fund (UNICEF) (2005) Changing a harmful social convention: Female genital mutilation/cutting. UNICEF Innocenti Research Centre. New York.

2. UN Women (2013) Breaking the Silence on Violence against Indigenous Girls, Adolescents and Young Women. United Nations Entity for Gender Equality and the Empowerment of Women.

3. Ohchr, Unaids, Undp, Uneca, Unesco, et al. (2008) Eliminating Female genital mutilation An interagency statement. Geneva WHO.

4. WHO (2020) Female genital mutilation Fact Sheet. WHO.

5. UNICEF (2013) Female Genital Mutilation/Cutting: a statistical overview and exploration of the dynamics of change. Reproductive Health Matters: 21.

6. UNFPA (2019) 5 ways female genital mutilation undermines the health of women and girls. Available from: https://www.unfpa.org/news/5-ways-female-genital-mutilationundermines-health-women-and-girls

7. UNFPA/UNICEF (2015) Annual Report UNFPA-UNICEF Joint Programme on Female Genital Mutilation/Cutting: Accelerating Change.

8. Wasike ATK (2016) The challenge of eradicating FGM among Kenya's Maasai, DW, Africa.

9. Ann-Marie W(2013) Refworld | Country Profile: FGM in Kenya. 2013.

10. Gitau T, Kusters L, Kok M, Van Der Kwaak A (2016) A baseline study on child marriage, teenage pregnancy and female genital mutilation/ cutting in Kenya. List of tables and figures 5 list of acronyms and key terms 6 executive summary 7 . Available from: https://www.kit.nl/wp-content/uploads/2018/10/Baseline-report-Kenya-Yes-I-Do.pdf

11. Loaiza E, Liang M. (2013) adolescent pregnancy: A review of the evidence adolescent pregnancy: A Review of the Evidence UNFPA, New York.

12. United Nations Children's Fund (UNICEF) (2017) Female Genital Mutilation / Cutting and Child Marriage among the Rendille, Maasai , Pokot, Samburu and Somali Communities in Kenya. Nairobi.

13. Kenya National Bureau of Statistics (KNBS) (2015) Kenya 2014 Demographic and Health Survey: 603.
14. Graamans EP, Smet E, ten Have S (2019) Legislation against girl circumcision: a cultural psychological understanding of prohibition. Sex Reprod Heal Matters 27: 307-309.

15. Muthumbi J, Svanemyr J, Scolaro E, Temmerman M, Say L (2016) Female genital mutilation: A literature review of the current status of legislation and policies in 27 African countries and Yemen. Afr J Reprod Health 19: 32-40. [Crossref]

16. Mpinga EK, Macias A, Hasselgard-Rowe J, Kandala NB, Félicien TK, et al. (2016) Female genital mutilation: a systematic review of research on its economic and social impacts across four decades. Glob Health Action 9: 31489. [Crossref]

17. Kandala NB, Ezejimofor MC, Uthman OA, Komba P (2018) Secular trends in the prevalence of female genital mutilation/cutting among girls: A systematic analysis. BMJ Glob Heal 3: e000549. [Crossref]

18. Shell-Duncan B, Gathara D, Moore Z (2017) Female genital mutilation/cutting in kenya: is change taking place? Descriptive statistics from four waves of demographic and health surveys.

19. Amref Health Africa. Our vision to end FGM/C by 2030:1-6. Available from: https://view. publitas.com/amref-flying-doctors/amref-our-vision-to-end-fgm-c-by-2030/page/1

20. National Council for Law Reporting (2011) Prohibition of Female Genital Mutilation Act.

21. KNBS (2019) 2019 Kenya Population and Housing Census Results - Kenya National Bureau of Statistics.

22. Krueger RA, Casey MA(2014) Casey - Focus Groups_A Practical Guide for Applied Research. SAGE Publications Ltd. pp: 1-560.

23. Shell-Duncan B, Herniund Y (2006) Are there "stages of change" in the practice of female genital cutting?: Qualitative research findings from Senegal and The Gambia. Afr J Reprod Health 10: 57-71. [Crossref]

24. Hayford SR (2005) Conformity and change: Community effects on female genital cutting in Kenya. J Health Soc Behav 46: 121-140. [Crossref]

25. Chege J, Askew I, Liku J (2001) An Assessment of the Alternative Rites Approach fo Encouraging Abandonment of Female Genital Mutilation in Kenya. Available from: https://knowledgecommons.popcouncil.org/departments_sbsr-rh/10/

26. Oloo Habil, Monica Wanjiru KNJ (2001) Female Genital Mutilation practices in Kenya The role of Alternat ive Rites of Passage: A case study of Kisii and Kuria districts. Nairobi.

27. Unfpa/Unicef (2013) Joint Evaluation Unfpa-Unicef Joint Programme on Female Genital Mutilation/Cutting: Accelerating Change 2008 - 2012. pp: 1-113.

28. Mackie G, Lejeune J (2009) Social Dynamics of Abandonment of Harmful Practices: a New Look at the Theory. UNICEF Innocenti Working paper.

29. Johansen REB, Diop NJ, Laverack G, Leye E (2013) What Works and What Does Not: A Discussion of Popular Approaches for the Abandonment of Female Genital Mutilation. Obstet Gynecol Int: 348248. [Crossref]

30. Ethiopia: Social dynamics of abandonment of harmful practices. Experiences in four locations.

31. Egberts F, Demenint M (2018) Yes I Do Alliance Midterm Review 2016 to June 2018 Synthesis report, Plan International Netherlands. Netherlands.

32. UNFPA (2013) Driving Forces in Outlawing the Practice of Female Genital Mutilation/ Cutting in Kenya, Uganda and Guinea-Bissau.

33. Gitagno JF (2015) Effects of Alternative Rite Of Passage on Girls' Education among the Keiyo Community of Elgeyo Marakwet County-Kenya. IOSR J Humanit Soc Sci 20: $98-110$.

34. Koski A, Clark S, Nandi A (2017) Has Child Marriage Declined in sub-Saharan Africa? An Analysis of Trends in 31 Countries. Popul Dev Rev 43: 7-29.

35. Gitau T, Kusters L, Kok M, Van Der Kwaak A (2016) A baseline study on child marriage, teenage pregnancy and female genital mutilation/ cutting in Kenya list of tables and figures 5 list of acronyms and key terms 6 executive summary 7 .

36. Loaiza E, Wong S (2012) Marrying Too Young - End Child Marriage. pp: 1-76 Available from: https://www.unfpa.org/sites/default/files/pub-pdf/MarryingTooYoung. pdf

Copyright: (C2020 Muhula S. This is an open-access article distributed under the terms of the Creative Commons Attribution License, which permits unrestricted use, distribution, and reproduction in any medium, provided the original author and source are credited. 